\title{
Structural Characterization of Surfactant-Coated Bimetallic Cobalt/Nickel Nanoclusters by XPS, EXAFS, WAXS, and SAXS
}

\author{
Luisa Sciortino, ${ }^{\dagger}$ Francesco Giannici, ${ }^{\dagger}$ Antonino Martorana, ${ }^{\dagger}$ Angela Monia Ruggirello, ${ }^{\dagger}$ \\ Vincenzo Turco Liveri, ${ }^{\dagger}$ Giuseppe Portale, ${ }^{\neq}$Maria Pia Casaletto, ${ }^{\S}$ and Alessandro Longo, ${ }^{*} \S$ \\ ${ }^{\dagger}$ Dipartimento di Chimica "Stanislao Cannizzaro", Università di Palermo, Parco D’Orleans II, I-90128 Palermo, Italy \\ ${ }^{\ddagger}$ Netherlands Organization for Scientific Research (NWO), 6 rue Jules Horowitz, BP220, 38043 Grenoble Cedex, France \\ §Istituto per lo Studio dei Materiali Nanostrutturati, CNR, Via Ugo La Malfa 153, I-90146 Palermo, Italy
}

\begin{abstract}
Cobalt-nickel bimetallic nanoparticles were synthesized by changing the sequence of the chemical reduction of $\mathrm{Co}$ (II) and $\mathrm{Ni}$ (II) ions confined in the core of bis(2ethylhexyl)phosphate ${ }_{2}$, and $\mathrm{Ni}(\mathrm{DEHP})_{2}$. The reduction was carried out by mixing, sequentially or contemporaneously, fixed amounts of $n$-heptane solution of $\mathrm{Co}(\mathrm{DEHP})_{2}$ and $\mathrm{Ni}(\mathrm{DEHP})_{2}$ micelles with a solution of sodium borohydride in ethanol at a fixed (reductant)/(total metal) molar ratio. This procedure involves the rapid formation of surfactant-coated nanoparticles, indicated as $\mathrm{Co} / \mathrm{Ni}$ (Co after $\mathrm{Ni}$ ), $\mathrm{Ni} / \mathrm{Co}$ ( $\mathrm{Ni}$ after $\mathrm{Co}$ ), and $\mathrm{Co}+\mathrm{Ni}$ (simultaneous), followed by their slow separation as nanostructures embedded in a sodium bis(2-ethylhexyl)phosphate matrix. The resulting composites, together with those obtained by reducing the $n$-heptane solutions of pure $\mathrm{Co}(\mathrm{DEHP})_{2}$ or $\mathrm{Ni}(\mathrm{DEHP})_{2}$, were characterized by XPS, EXAFS, WAXS, and SAXS. The data analysis confirms the presence of nanometer-sized surfactant-coated cobalt, nickel, and cobalt/nickel particles. As expected, the composition and internal structure of cobalt/nickel bimetallic nanoparticles are influenced by the preparation sequence as well as by the "chemical

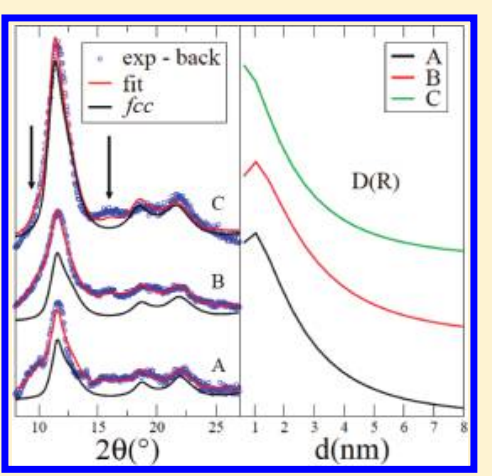
affinity" between the surfactant and the metal. However, some atomic-scale physicochemical processes play a subtle role in determining the structural features of bimetallic nanoparticles. Further effects due to the competition between nanoparticle growing process and surfactant adsorption at the nanoparticle surface were observed.
\end{abstract}

\section{INTRODUCTION}

The preservation of nanoparticle identity from agglomeration and chemical decomposition, allowing size-control and longterm storage without losing unique properties, is one of the most stringent requirements of an effective nanoparticle synthetic strategy. This can be achieved by the use of a suitable coating agent, which could also involve an easy separation of nanoparticles from the reaction medium. ${ }^{1-5}$

A peculiar class of coating agents is composed of surfactants which, owing to their amphiphilic nature, are able to physically or chemically adsorb at the nanoparticle surface through their hydrophilic heads and to build up a hydrophobic layer formed by the oriented alkyl chains, thus hindering the nanoparticle 3growing/coalescence processes and, at the same time, allowing a protection of their chemical composition from most external reactants. Further advantages of surfactants arise from their functionalization as carriers of nanoparticle precursors and their ability of self-assembly as pure components, to form a supramolecular structure that directs the nanoparticle $2 \mathrm{D}$ and $3 \mathrm{D}$ spatial arrangement. $^{5-8}$ Other requirements arise when one aims at the production of nanoparticles composed of two or more components, in which a well-defined structural arrangement is crucial to control their properties. In such a case, the control of the composition and the internal structure becomes of the utmost importance to modulate the physicochemical features of the nanoparticles. In principle, this can be achieved by varying the synthetic protocol. ${ }^{9-12}$
The core-shell nanoparticles can be effectively formed using separate reduction reactions in two stages with different reaction temperatures through the heterogeneous nucleation process. For example, $\mathrm{Cu}-\mathrm{Ni}$ core-shell nanoparticles have been prepared using this technique. Recently, Yamauchi et al. showed that the shapes of the $\mathrm{Ni}-\mathrm{Co}$ nanoparticles can be easily controlled using different nickel precursors. It was also shown that the shape of the $\mathrm{Ni}$ core plays a key role in determining the final shape of a NiCo (core-shell) nanocrystal, because $\mathrm{Ni}$ nanoparticles act as catalysts for the redox reaction of the $\mathrm{Co}^{2+}$ ions. ${ }^{13}$ However, this mechanism has been investigated for metal clusters with diameters in the range of $40-50 \mathrm{~nm}$, and the possibility of exchanging the two metals in the core of the nanoparticles was not investigated.

In order to finely control the structure, chemical composition, and growth of nanosized $\mathrm{Co}-\mathrm{Ni}$ particles of a few nanometers in diameter, we investigated the effect of changing the sequence of the chemical reduction of $\mathrm{Co}^{2+}$ and $\mathrm{Ni}^{2+}$ ions in the reverse micelle solutions of cobalt bis(2-ethylhexyl)phosphate, $\mathrm{Co}(\mathrm{DEHP})_{2}$, and nickel bis(2-ethylhexyl)phosphate, $\mathrm{Ni}(\mathrm{DEHP})_{2}{ }^{14}$

In particular, the reduction reactions were carried out by mixing, sequentially or contemporaneously, fixed amounts of $0.3 \mathrm{M}$

Received: January 11, 2011

Revised: February 3, 2011

Published: March 03, 2011 
$n$-heptane solution of $\mathrm{Co}(\mathrm{DEHP})_{2}$ and $\mathrm{Ni}(\mathrm{DEHP})_{2}$ with a solution of sodium borohydride in ethanol ( $1 \%$ weight) at a reductant to total metal molar ratio of 4 . This procedure involves the rapid formation of surfactant-coated bimetallic nanoparticles, followed by their slow separation as nanostructures embedded in a sodium bis(2-ethylhexyl)phosphate matrix.

The resulting nanostructured samples were investigated by XPS, EXAFS, and WAXS in order to determine the oxidation state and local environment of cobalt and nickel and by SAXS to gain structural information on both nanoparticles and surfactant matrix in a wide length scale range. For comparison, we investigated also samples obtained by reduction of the $n$-heptane solutions of $\mathrm{Co}(\mathrm{DEHP})_{2}$ or $\mathrm{Ni}(\mathrm{DEHP})_{2}$ with sodium borohydride.

In this paper we present evidence of stable nanometer-sized Co, $\mathrm{Ni}$, and $\mathrm{Co}-\mathrm{Ni}$ clusters (whose atomic scale structure and composition are probed by XPS, EXAFS, and WAXS), which are embedded in higher superstructures (whose features are probed by SAXS).

\section{EXPERIMENTAL SECTION}

Bis(2-ethylhexyl)phosphoric acid (HDEHP, Sigma, 97\%), sodium hydroxide (Riedel-de Haen, 99\%), n-heptane (Aldrich, 99\% spectrophotometric grade), cobalt(II) nitrate (Aldrich, 99.9\%), nickel(II) nitrate (Aldrich, crystalline), sodium borohydride $\left(\mathrm{NaBH}_{4}\right.$, Aldrich), and absolute ethanol (Fluka, $\left.\geq 99.8 \%\right)$ were used as received. Cobalt bis (2-ethylhexyl)phosphate $\left(\mathrm{Co}(\mathrm{DEHP})_{2}\right)$ and nickel bis (2-ethylhexyl)phosphate $\left(\mathrm{Ni}(\mathrm{DEHP})_{2}\right)$ were prepared by mixing appropriate amounts of an aqueous solution of $\mathrm{Co}\left(\mathrm{NO}_{3}\right)_{2}$ or $\mathrm{Ni}\left(\mathrm{NO}_{3}\right)_{2}$ with a $10^{-2} \mathrm{M}$ aqueous solution of $\mathrm{HDEHP}$ neutralized with $\mathrm{NaOH}$. After aging, the precipitates were washed several times and dried under vacuum at room temperature. ${ }^{11}$

Cobalt bis(2-ethylhexyl)phosphate/ $n$-heptane and nickel bis(2-ethylhexyl)phosphate/ $n$-heptane solutions were prepared at a fixed surfactant concentration of $0.3 \mathrm{M}$. The solution of sodium borohydride in ethanol ( $1 \%$ weight) was prepared immediately before use. In order to obtain complete reduction of $\mathrm{Co}$ (II) and $\mathrm{Ni}$ (II), appropriate amounts of the two surfactant $/ n$-heptane solutions were mixed with $\mathrm{NaBH}_{4}$ /ethanol at a reductant to metal molar ratio of $4(0.7 \mathrm{~mL}$ of metal-surfactant/heptane + $8.5 \mathrm{~mL}$ of $\mathrm{NaBH}_{4}$ / ethanol). Immediately after the addition of the sodium borohydride solution to the surfactant(s)/n-heptane solution, the mixtures turned black, suggesting the formation of very fine $\mathrm{Co}, \mathrm{Ni}$, and $\mathrm{Co}-\mathrm{Ni}$ powders, according to the reactions

$$
\mathrm{Co}(\mathrm{DEHP})_{2}+2 \mathrm{NaBH}_{4} \rightarrow \mathrm{Co}+2 \mathrm{NaDEHP}+\mathrm{B}_{2} \mathrm{H}_{6}+\mathrm{H}_{2}
$$

$$
\mathrm{Ni}(\mathrm{DEHP})_{2}+2 \mathrm{NaBH}_{4} \rightarrow \mathrm{Ni}+2 \mathrm{NaDEHP}+\mathrm{B}_{2} \mathrm{H}_{6}+\mathrm{H}_{2}
$$

In addition to the samples composed of surfactant-coated Co or Ni monometallic nanoparticles, three different samples were prepared as follows:

(i) Sample Co/Ni was obtained by adding the ethanol solution of sodium borohydride to the $n$-heptane solution of $\mathrm{Ni}(\mathrm{DEHP})_{2}$ and, after a few minutes, the $n$-heptane solution of $\mathrm{Co}(\mathrm{DEHP})_{2}$.

(ii) Sample Ni/Co was obtained by adding the ethanol solution of sodium borohydride to the $n$-heptane solution of $\mathrm{Co}(\mathrm{DEHP})_{2}$ and, after a few minutes, the $n$-heptane solution of $\mathrm{Ni}(\mathrm{DEHP})_{2}$. (iii) Sample Co $+\mathrm{Ni}$ was obtained by adding the ethanol solution of sodium borohydride to the mixed $n$-heptane equimolar solution of $\mathrm{Ni}(\mathrm{DEHP})_{2}$ and $\mathrm{Co}(\mathrm{DEHP})_{2}$.

The black precipitates, obtained according to these procedures and essentially composed of the surfactant soft-coated nanoparticles, were stored in closed glass vials before measurements. The surface chemical composition of the samples was investigated by XPS. Photoemission spectra were collected by a VG Microtech ESCA 3000 Multilab spectrometer, equipped with a standard $\mathrm{Al} \mathrm{K} \mathrm{K}_{\alpha}$ excitation source $(h v=1486.6 \mathrm{eV})$ and a nine-channeltrons detection system. The hemispherical analyzer was operated in the CAE mode, at a constant pass energy of $20 \mathrm{eV}$. The binding energy (BE) scale was calibrated by measuring the $\mathrm{C} 1 \mathrm{~s}$ peak $(\mathrm{BE}=285.1 \mathrm{eV})$ from the surface contamination, and the accuracy of the measure was $\pm 0.1 \mathrm{eV}$. Photoemission data were collected and processed by using the VGX900 software. Data analysis was performed by a nonlinear least-squares curve-fitting program using a properly weighted sum of Lorentzian and Gaussian component curves, after background subtraction according to Shirley and Sherwood. ${ }^{15,16}$ Surface relative atomic concentrations were calculated by a standard quantification routine, including Wagner's energy dependence of attenuation length and a standard set of VG Escalab sensitivity factors. The uncertainty in the atomic concentration is of the order of $10 \%$. $^{17}$

High-resolution wide-angle X-ray scattering (WAXS) patterns were recorded at the ID31 beamline of the European Synchrotron Radiation Facility (ESRF) in trasmission geometry and fixed wavelength (0.400 $00 \AA$ A). Samples were loaded in $1.5 \mathrm{~mm}$ glass capillaries. The diffracted radiation was measured in the $2^{\circ}-38^{\circ}$ $2 \theta$ range. The experimental setup for simultaneous EXAFS and SAXS measurements on beamline BM26 of ESRF was recently described elsewhere, and it will only be briefly recalled here. ${ }^{12}$ The primary beam intensity is measured with an ionization chamber. A vacuum flight tube is placed between the sample and the position-sensitive detector used for the collection of SAXS pattern. A beam stop with an integrated PIN photodiode is placed close to the exit window. The PIN photodiode is used to measure the transmitted X-rays (and hence the XAS spectrum), while a $1 \mathrm{D}$ quadrant gas-filled multiwire detector with $200 \mu \mathrm{m}$ spatial resolution is used to record the SAXS data. XAS data were collected at the cobalt K-edge $(7.7 \mathrm{keV})$ with a resolution of 1.5 $\mathrm{eV}$. The EXAFS data analysis was carried out using the Viper program. ${ }^{18}$ All the data were extracted using a Bayesian smoothing algorithm. The Co K-edge data fitting was performed in $R$ space, windowing data from 1 to $4.3 \AA$. The data were weighted by $k^{3}$. FEFF8.4 ab initio code was used to generate amplitudes and phase shift for the scattering paths. The phase shift and the backscattering amplitude were calibrated by using Co bulk as reference sample, with $S_{0}{ }^{2}$ and $\Delta E_{0}$ set to fixed values. The SAXS data were recorded at $14 \mathrm{keV}$ using the quadrant detector and a sample-to-detector distance of around $2 \mathrm{~m}$. This configuration allowed to record SAXS data in the $0.071-0.45 \AA^{-1} q$ range, where $q$ is the modulus of the scattering vector $(q=4 \pi \sin (\theta) /$ $\lambda$ ). The four observed diffraction maxima of a standard silver behenate sample were used for the scattering vector calibration. Standard procedures were applied to correct SAXS data for the contributions due to the scattering of air and sample holder windows. 
Table 1. XPS Surface Chemical Composition of the Investigated Samples ${ }^{a}$

$\begin{array}{lcccccc}\text { sample } & \text { C 1s } & \text { O 1s } & \text { Co 2p } & \text { Ni 2p } & \text { P 2p } & \text { Na 1s } \\ \mathrm{BE}(\mathrm{eV}) & 285.1 & 531.7 & 781.3 & 855.6 & 134.0 & 1071.0 \\ \mathrm{Ni} & 51.5 & 30.9 & - & 2.8 & 2.3 & 12.5 \\ \mathrm{Co} & 47.5 & 29.6 & 7.1 & - & 2.6 & 13.2 \\ \mathrm{Co}+\mathrm{Ni} & 33.2 & 37.3 & 5.0 & 2.6 & 4.3 & 17.6 \\ \mathrm{Ni} / \mathrm{Co} & 45.5 & 26.8 & 7.4 & 0.3 & 2.9 & 17.1 \\ \mathrm{Co} / \mathrm{Ni} & 43.1 & 29.1 & 11.9 & - & 2.8 & 13.1 \\ { }^{a} \text { Elemental concentration is expressed as atom \%. } & & \end{array}$

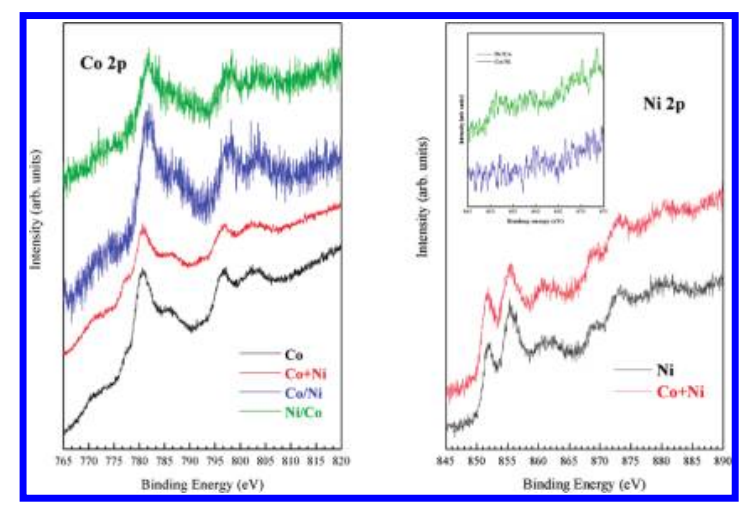

Figure 1. XPS spectra of the Co $2 p$ and Ni $2 p$ photoelectron peaks in the investigated samples.

\section{RESULTS AND DISCUSSION}

3.1. XPS Analysis. The surface chemical composition of pure $\mathrm{Co}$, pure $\mathrm{Ni}, \mathrm{Co}+\mathrm{Ni}, \mathrm{Co} / \mathrm{Ni}$, and $\mathrm{Ni} / \mathrm{Co}$ samples was determined by XPS, and a summary of the quantitative results, expressed as atomic percentage, is listed in Table 1. Pure cobalt and pure nickel samples were taken as references.

P 2p and Na 1s photoelectron peaks were detected on the surface of all the investigated samples. The detection of sodium and phosphor evidenced that the surfactant compound, i.e., sodium bis(2-ethylhexyl)phosphate, acting as capping agent and embedding matrix, was still present on the sample surfaces. On the $\mathrm{Co}+\mathrm{Ni}$ surface an higher concentration of Co atoms was determined with respect to $\mathrm{Ni}$ atoms, the atomic ratio being almost 2:1. Both $\mathrm{Co}+\mathrm{Ni}$ and $\mathrm{Ni} / \mathrm{Co}$ samples exhibited a comparable concentration of $\mathrm{Co}$ atoms, even if a relatively small surface content of $\mathrm{Ni}$ was ascertained on the $\mathrm{Ni} / \mathrm{Co}$ sample. This quite unexpected result could be rationalized considering that (i) Co atoms prefer to migrate/stay at the nanoparticle surface, (ii) Co atoms display enhanced affinity for the surfactant head group, and (iii) the deposition rate of Co atoms on the nanoparticle surface is much lower than that of $\mathrm{Ni}$ atoms. In the XPS spectrum of the $\mathrm{Co} / \mathrm{Ni}$ sample, the presence of only Co suggested that $\mathrm{Ni}$ was essentially located in the core of the nanoparticles coated by cobalt, as expected. ${ }^{13}$

XPS raw spectra of the Co $2 p$ and Ni $2 p$ photoelectron peaks in the investigated samples are reported in Figure 1. In order to ascertain the oxidation state of the elements on the sample surface, a curve-fitting procedure of the Ni $2 \mathrm{p}_{3 / 2}$ and Co $2 \mathrm{p}_{3 / 2}$ photoelectron peaks was performed, and the results for the $\mathrm{Co}+$ $\mathrm{Ni}$ sample, chosen as representative, are shown in Figure 2. The presence of $\mathrm{Co}^{2+}$ species on the surface was confirmed by the

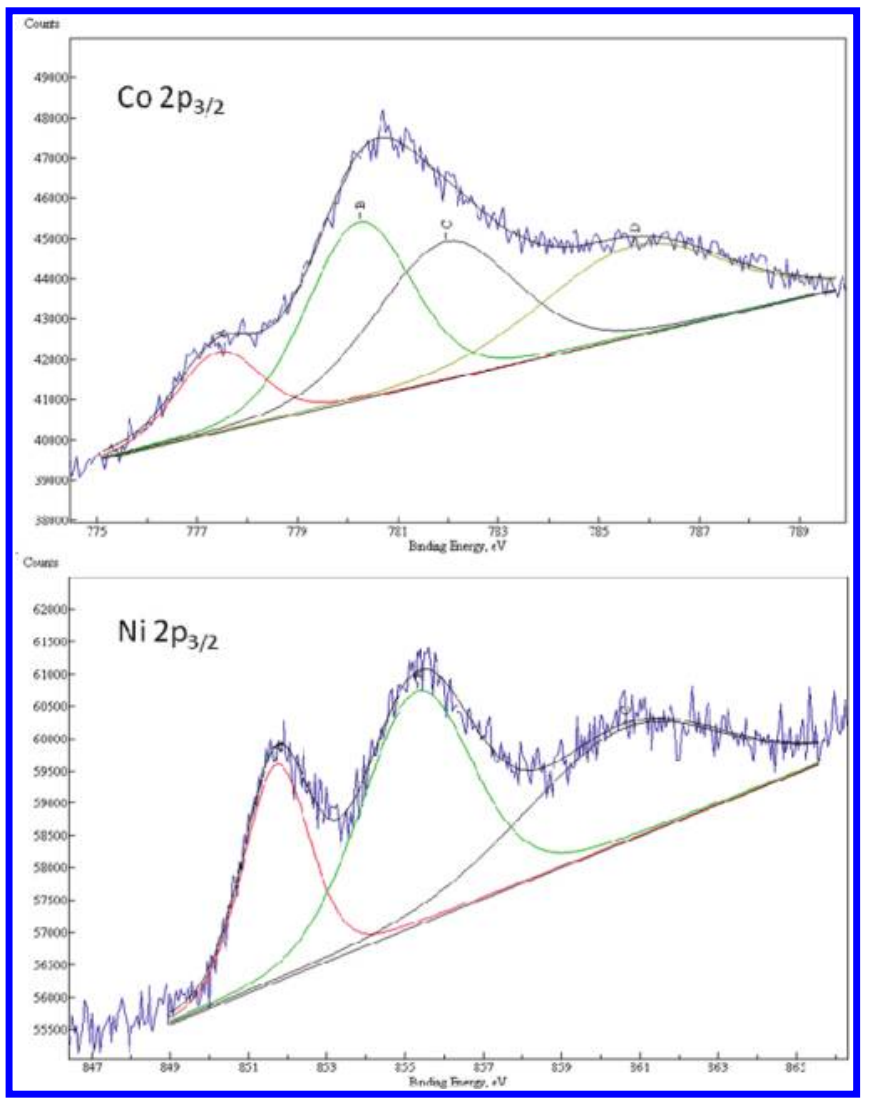

Figure 2. XPS curve-fitting of the Co $2 \mathrm{p}_{3 / 2}$ and $\mathrm{Ni} 2 \mathrm{p}_{3 / 2}$ photoelectron peaks in the $\mathrm{Co}+\mathrm{Ni}$ sample.

Table 2. XPS Curve-Fitting Results Expressed as Peak Area Percentage (Total Peak Area $=100 \%$ )

\begin{tabular}{|c|c|c|c|c|c|c|c|c|}
\hline \multirow{2}{*}{$\begin{array}{c}\text { sample } \\
\mathrm{BE}(\mathrm{eV})\end{array}$} & \multicolumn{3}{|c|}{$\mathrm{O} 1 \mathrm{~s}$} & \multicolumn{2}{|c|}{$\mathrm{Ni} 2 \mathrm{p}_{3 / 2}$} & \multicolumn{3}{|c|}{ Co $2 p_{3 / 2}$} \\
\hline & 530.6 & 532.0 & 535.4 & 851.9 & 855.4 & 777.3 & 780.4 & 782.0 \\
\hline assignment & oxide & $\mathrm{OH}^{-}$ & $\mathrm{H}_{2} \mathrm{O}$ & $\mathrm{Ni}^{0}$ & $\mathrm{Ni}(\mathrm{OH})_{2}$ & $\mathrm{Co}^{0}$ & $\mathrm{CoO}$ & $\mathrm{Co}(\mathrm{OH})_{2}$ \\
\hline $\mathrm{Ni}$ & 11.0 & 82.3 & 6.6 & 30.8 & 69.2 & - & - & - \\
\hline Co & 44.3 & 50.6 & 5.1 & - & - & 11.2 & 60.8 & 28.1 \\
\hline $\mathrm{Co}+\mathrm{Ni}$ & 32.9 & 57.5 & 9.6 & 35.8 & 64.2 & 15.2 & 41.6 & 43.2 \\
\hline $\mathrm{Ni} / \mathrm{Co}$ & 30.1 & 62.2 & 7.8 & - & - & 8.9 & 59.2 & 31.9 \\
\hline $\mathrm{Co} / \mathrm{Ni}$ & 22.2 & 62.2 & 15.6 & - & - & 8.1 & 26.5 & 65.5 \\
\hline
\end{tabular}

diagnostic satellite peak at $\mathrm{BE} \sim 786 \mathrm{eV}$. The $\mathrm{Ni} 2 \mathrm{p}_{3 / 2}$ photoelectron peak was composed of a principal component located at $\mathrm{BE}=855.4 \mathrm{eV}$, due to the presence of $\mathrm{Ni}(\mathrm{OH})_{2}$ and $/$ or $\mathrm{NiOOH}$ species and a second component at $\mathrm{BE}=851.9 \mathrm{eV}$, assigned to $\mathrm{Ni}^{0}$ species. The occurrence of $\mathrm{Ni}^{2+}$ ions on the samples surface was confirmed by the satellite peak at $\mathrm{BE} \sim 861 \mathrm{eV}$, as shown in Figure 2. Furthermore, the $\mathrm{O} 1 \mathrm{~s}$ peak was deconvoluted into three components at $\mathrm{BE}=530.6,532.0$, and $535.4 \mathrm{eV}$, which can be assigned to oxide, hydroxide, and/or phosphate species and to adsorbed water, respectively. ${ }^{19,20}$

A summary of XPS curve-fitting results expressed as peak area percentage (total peak area $=100 \%$ ) is reported in Table 2. About the same percentage of $\mathrm{Ni}^{0}$ is found in the pure $\mathrm{Ni}$ and $\mathrm{Co}+\mathrm{Ni}$ nanoparticles, and this fraction is higher than that corresponding to $\mathrm{Co}^{0}$ species in pure $\mathrm{Co}, \mathrm{Co}+\mathrm{Ni}, \mathrm{Ni} / \mathrm{Co}$, and $\mathrm{Co} / \mathrm{Ni}$ nanoparticles. 


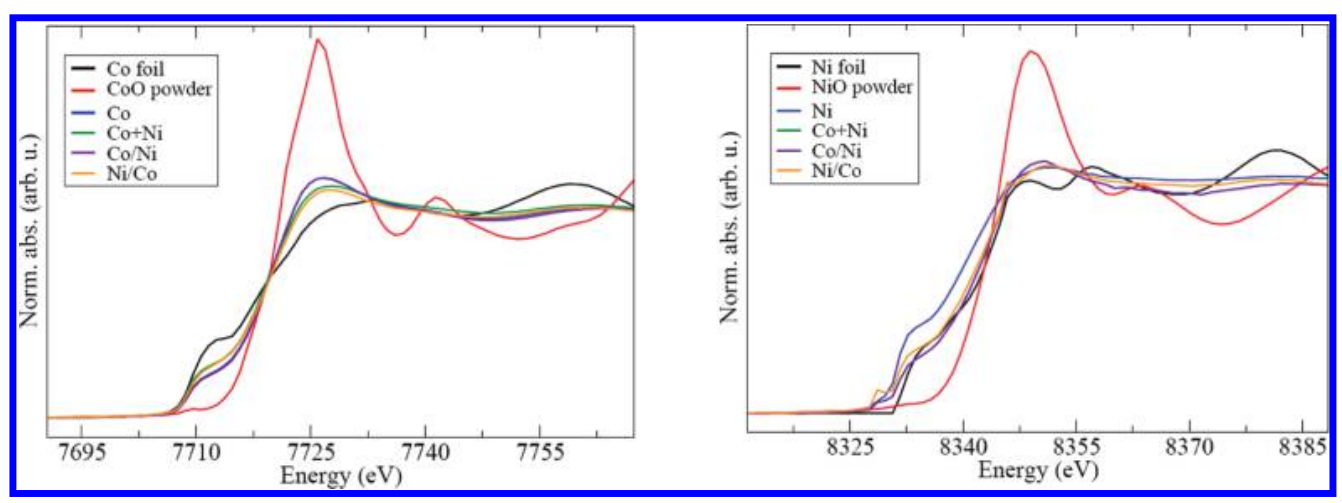

Figure 3. XANES spectra of investigated samples (left, Co edge; right, Ni edge).

Table 3. Nanoparticle Composition from the Analysis of the XANES Edges

\begin{tabular}{lrrrr} 
sample & $\mathrm{Ni}^{0}$ & $\mathrm{Ni}^{2+}$ & $\mathrm{Co}^{0}$ & $\mathrm{Co}^{2+}$ \\
$\mathrm{Ni}$ & $91 \%$ & $9 \%$ & - & - \\
$\mathrm{Co}$ & - & - & $72 \%$ & $28 \%$ \\
$\mathrm{Co}+\mathrm{Ni}$ & $83 \%$ & $17 \%$ & $80 \%$ & $20 \%$ \\
$\mathrm{Ni} / \mathrm{Co}$ & $85 \%$ & $15 \%$ & $82 \%$ & $18 \%$ \\
$\mathrm{Co} / \mathrm{Ni}$ & $83 \%$ & $17 \%$ & $72 \%$ & $28 \%$ \\
\hline
\end{tabular}

This indicates that in our experimental conditions nickel is less prone to be oxidized than cobalt. The relevant presence of cobalt in the oxidized form of $\mathrm{Co}^{2+}$ in both the $\mathrm{Ni} / \mathrm{Co}$ and $\mathrm{Co} / \mathrm{Ni}$ samples confirms that this atomic species could quite easily migrate at the nanoparticle surface. For the following discussion it is essential to bear in mind that XPS is a surface technique that allows to detect species preferentially located on the surface sample (sampling depth is about $3-10 \mathrm{~nm}$ ), and simple chemical reasoning suggests that atoms at the nanoparticle surface are more exposed to oxidation; then, they can interact with the surfactant molecules much better than those in the core. Therefore, this technique preferentially probes the chemical species at the nanoparticle surface and underestimates those in the core.

3.2. EXAFS Analysis. In order to obtain information on the valence state and coordination number of cobalt and nickel, and on the distance of surrounding atomic species, both the X-ray absorbing near-edge structure (XANES) features and the extended X-ray absorption fine structure (EXAFS) techniques were used. In Figure 3, XANES spectra of the investigated samples are shown, together with the bulk metals and oxides. The comparison of the XANES profiles suggests that in all the synthesized nanocomposites both cobalt and nickel are mainly in the metallic state, while a minor fraction of both metals is in the oxidized form. A quantitative analysis of the XANES edges of the samples, obtained by linear combination of $\mathrm{Co}$ and $\mathrm{CoO}$ reference spectra, allows the estimation of the nanoparticle composition in terms of metallic and oxidized forms, shown in Table 3 (uncertainty about 5\%). It must be noted that the concentration of the metals in the zero-valent state is between 72 and $91 \%$. The noticeable departure from the data of Table 2 emphasizes that the nanoparticle surface composition is strongly different from the average composition. Moreover, taking into account that spectra have been collected after about one month from sample preparation, this finding suggests that the surfactant coating effect and/or the formation
Table 4. Fitting Parameters Derived from EXAFS Data Analysis of All Samples at the K-Edge of $\mathrm{Ni}$ and $\mathrm{Co}^{a}$

\begin{tabular}{|c|c|c|c|c|c|c|}
\hline \multirow[b]{2}{*}{ sample } & \multicolumn{3}{|c|}{$\mathrm{Co}-\mathrm{M}$} & \multicolumn{3}{|c|}{$\mathrm{Co}-\mathrm{O}$} \\
\hline & $N$ & $R$ & $\sigma^{2}$ & $N$ & $R$ & $\sigma^{2}$ \\
\hline Co foil & 12 & 2.49 & 0.003 & & & \\
\hline $\mathrm{CoO}$ powder & 12 & 3.00 & 0.004 & 6 & 2.13 & 0.007 \\
\hline Co & 6 & 2.44 & 0.016 & 1.5 & 2.05 & 0.015 \\
\hline $\mathrm{Co}+\mathrm{Ni}$ & 5.4 & 2.45 & 0.013 & 1.3 & 2.04 & 0.022 \\
\hline $\mathrm{Ni} / \mathrm{Co}$ & 5.4 & 2.46 & 0.014 & 1.4 & 2.03 & 0.013 \\
\hline \multirow[t]{2}{*}{$\mathrm{Co} / \mathrm{Ni}$} & 5.5 & 2.46 & 0.016 & 1.5 & 2.03 & 0.013 \\
\hline & $\mathrm{Ni}-\mathrm{M}$ & & & $\mathrm{Ni}-\mathrm{O}$ & & \\
\hline sample & $N$ & $R$ & $\sigma^{2}$ & $N$ & $R$ & $\sigma^{2}$ \\
\hline $\mathrm{Ni}$ foil & 12 & 2.48 & 0.003 & & & \\
\hline $\mathrm{NiO}$ powder & 12 & 2.95 & 0.004 & 6 & 2.09 & 0.006 \\
\hline $\mathrm{Ni}$ & 3.4 & 2.45 & 0.011 & 0.6 & 2.05 & 0.017 \\
\hline $\mathrm{Co}+\mathrm{Ni}$ & 5.2 & 2.45 & 0.013 & 1.3 & 2.02 & 0.01 \\
\hline $\mathrm{Ni} / \mathrm{Co}$ & 5.5 & 2.45 & 0.012 & 1.2 & 1.98 & 0.012 \\
\hline $\mathrm{Co} / \mathrm{Ni}$ & 5.3 & 2.45 & 0.013 & 1.3 & 2.02 & 0.01 \\
\hline
\end{tabular}

${ }^{a} N$, coordination number; $R$, distance; $\sigma^{2}$, disorder factor; uncertainty is in the last digit ( $\mathrm{M}$ represents cobalt or nickel atoms).

of a thin oxide layer at the nanoparticle surface prevents effectively the oxidation of nanoparticles for at least one month.

3Further information was obtained by a detailed analysis of the EXAFS spectra. The EXAFS data of $\mathrm{Co}$ and $\mathrm{Ni}$ foils and clusters and the corresponding Fourier transforms are shown in Figures 4 and 5. The structural parameters $(\mathrm{Co}-\mathrm{Co} / \mathrm{Ni}$ and $\mathrm{Ni}-\mathrm{Ni} / \mathrm{Co}$ distances, $R$; first-shell coordination number, $N$ ) resulting from the fitting procedure of all the investigated samples are shown in Table 4.

As inferred from data in Table 4, the coordination number of the first shell of cobalt and nickel atoms in all the samples is lower than that in the bulk state. This finding, together with the reduction of the $\mathrm{Co}-\mathrm{M}$ and $\mathrm{Ni}-\mathrm{M}$ distances with respect to bulk, indicates that the nanoparticles are small and disordered. This is also in agreement with the strong increase of the disorder factors, of the order of $0.01 \AA^{2}$, with respect to the bulk counterparts.

According to the model by Borowski, ${ }^{21}$ it is possible to estimate the nanoparticle size (about $1-2 \mathrm{~nm}$ ) from the average coordination number of $\mathrm{Co}$ and $\mathrm{Ni}$ atoms in the samples. In the case of $\mathrm{Ni}$, a 


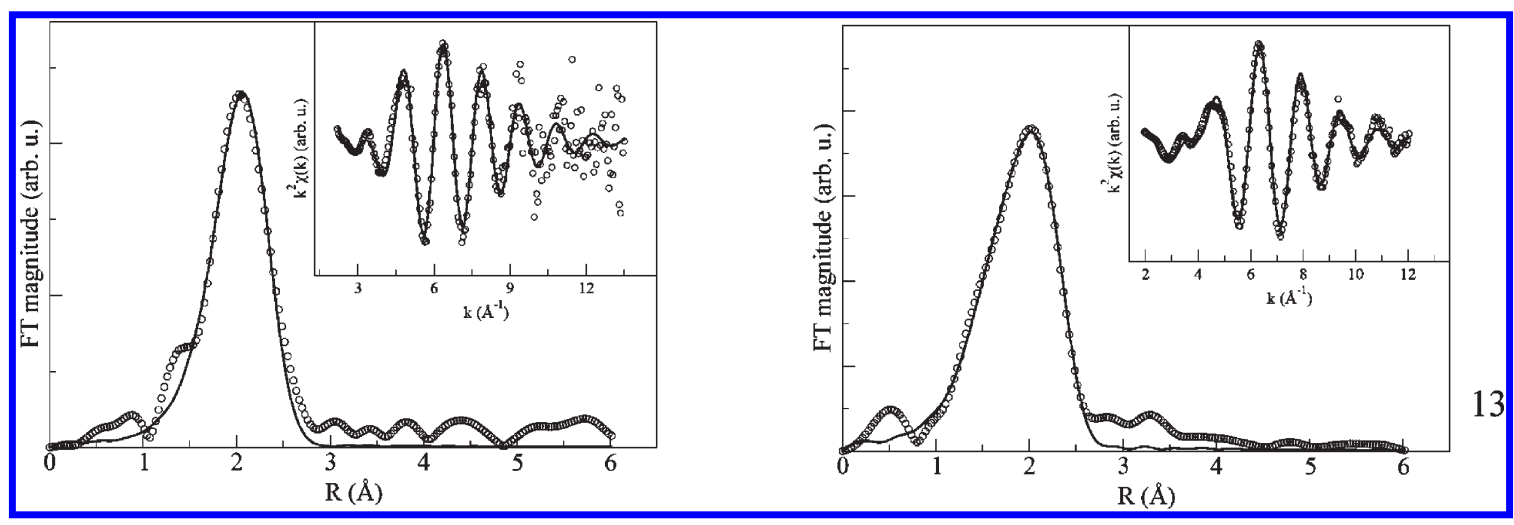

Figure 4. Fourier transform of the EXAFS data of Co foil (left) and Co cluster (right) on the Co K-edge ( $\bigcirc$, experimental; 一, fit). Fourier transforms are uncorrected for the phase shift (in the inset, the $k^{2}$-weighted EXAFS data of Co as foil and as cluster on the Co K-edge).

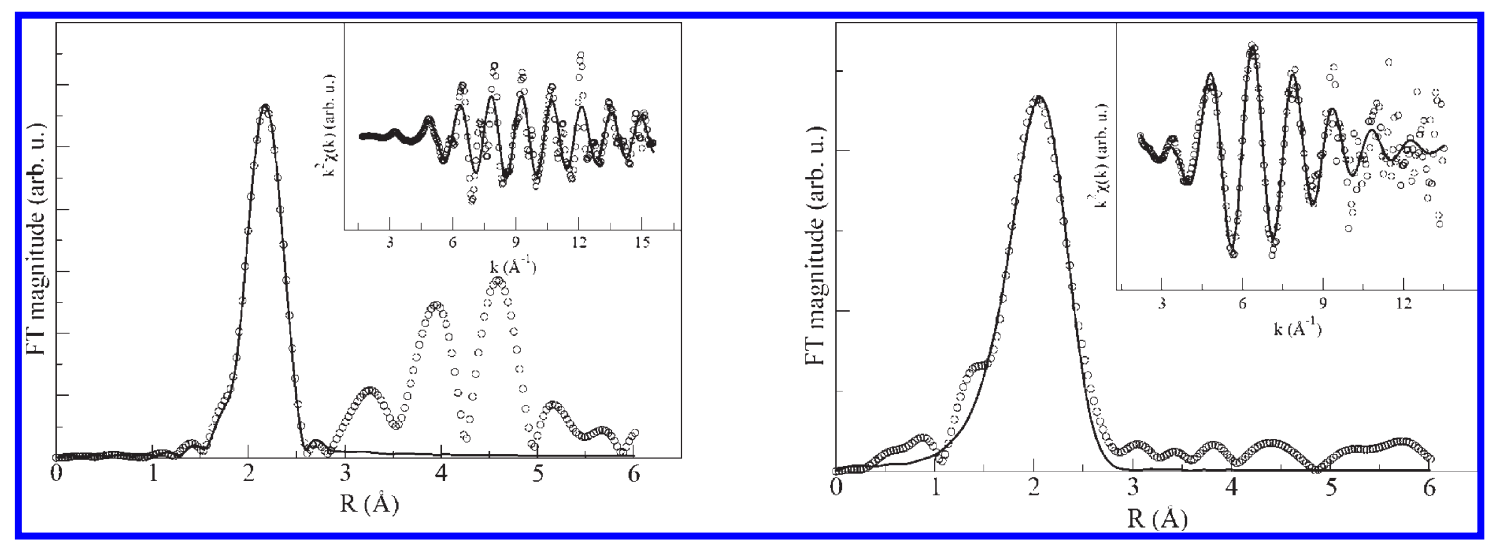

Figure 5. Fourier transform of the EXAFS data of Ni foil (left) and Ni cluster (right) on the Ni K-edge ( $\mathrm{O}$, experimental; —, fit). Fourier transforms are uncorrected for the phase shift (in the inset, the $k^{2}$-weighted EXAFS data of Ni as foil and as cluster on the Ni K-edge).

smaller size is observed, as witnessed by the lower coordination numbers. The very small size of the nanoparticles is also confirmed by the fact that only the first coordination shell is present in the EXAFS signal. In addition, the coordination of $\mathrm{Co}$ and $\mathrm{Ni}$ with oxygen atoms is clearly detected, probably due to the surfactant head groups together with a minor fraction of metal in the oxide form. In all the bimetallic combinations, the coordination of oxygen is observed in both $\mathrm{Co}$ and $\mathrm{Ni}$ local environments, thereby implying that both these atoms are present on the surface.

3.3. WAXS and SAXS Analysis. WAXS data analysis of some representative samples $(\mathrm{Co}, \mathrm{Co} / \mathrm{Ni}$, and $\mathrm{Ni} / \mathrm{Co})$ is shown in Figure 6. Patterns of the reference compounds are reported in Figure 7. As indicated by the peak broadening, the metal clusters exhibit very small particle sizes, confirming that they are in the nanometric scale. Moreover, the comparison with the references compounds confirms that they are mainly in the metallic state. According to the literature, ${ }^{2,23}$ and considering the low number of shells in the EXAFS data, which it makes difficult to discern the hcp and fcc arrangements, only the fcc structure was considered in the fitting analysis, although the hcp structure was tested and suggested similar results.

Then, following the model previously described, a log-normal distribution of diameters normalized over the different sizes was used to fit the WAXS data. Parameters accounting for the stacking faults and microstrain were added to the model. ${ }^{24}$ In the

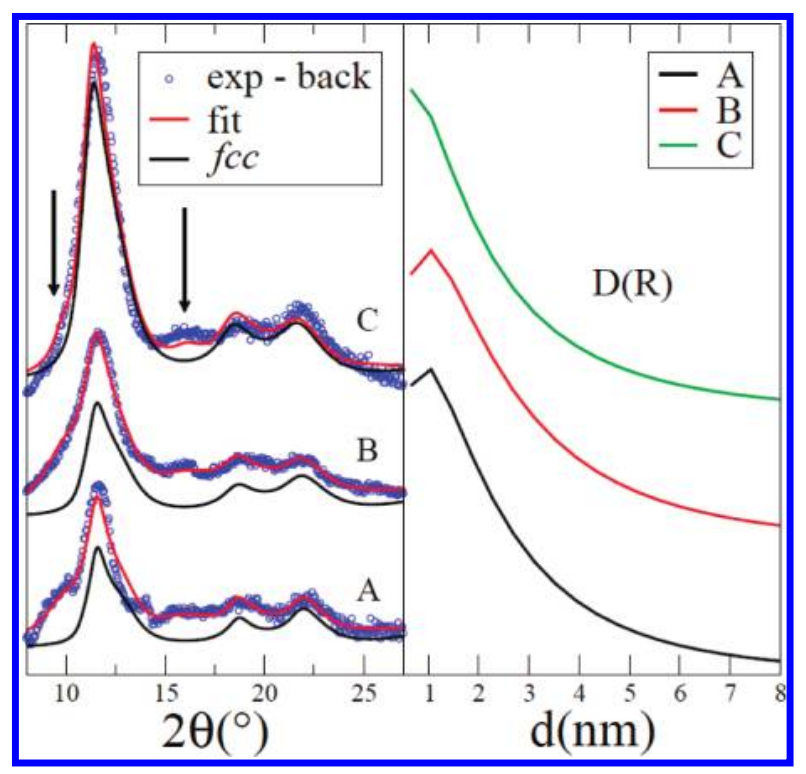

Figure 6. (Left) subtracted WAXS (blue $O$ ) and calculated data (red line) of $\mathrm{Co}, \mathrm{Co} / \mathrm{Ni}$, and $\mathrm{Ni} / \mathrm{Co}$ samples (A, B, and $\mathrm{C}$, respectively). The only fcc components (black line) are also shown. (Right) distribution functions of the diameters optimized for each sample. The arrows point to peaks position of surfactant component added in the analysis. 


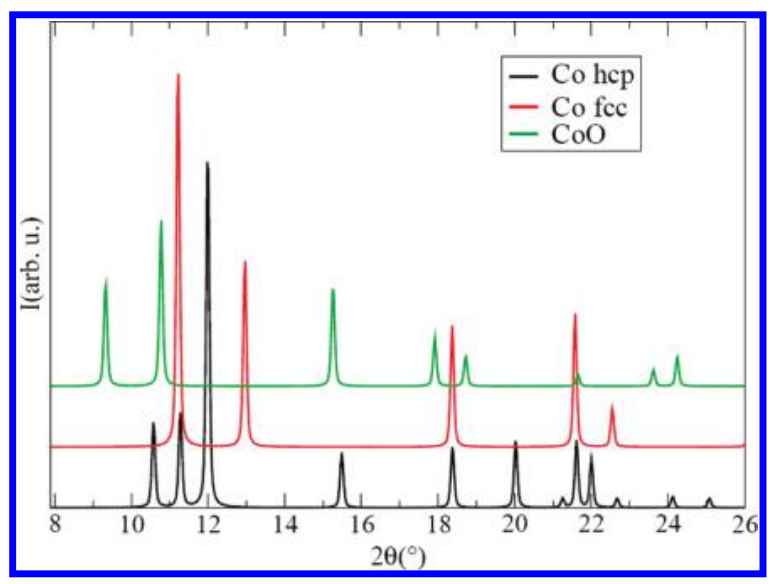

Figure 7. WAXS profiles of fcc Co, hcp Co, and $\mathrm{CoO}$ standards $(\lambda=0.4$ A) shifted for sake of clarity.

Table 5. Average Diameter, $\langle d\rangle$, Resulting from WAXS and SAXS Data Analysis ${ }^{a}$

\begin{tabular}{lcc} 
sample & $\langle d\rangle(\mathrm{nm})$ from WAXS & $\langle d\rangle(\mathrm{nm})$ from SAXS \\
$\mathrm{Co}$ & 1.7 & 1.9 \\
$\mathrm{Ni} / \mathrm{Co}$ & 1.7 & 1.3 \\
$\mathrm{Co} / \mathrm{Ni}$ & 1.8 & 1.5 \\
${ }^{a}$ Uncertainty is in the last digit. & \\
\hline
\end{tabular}

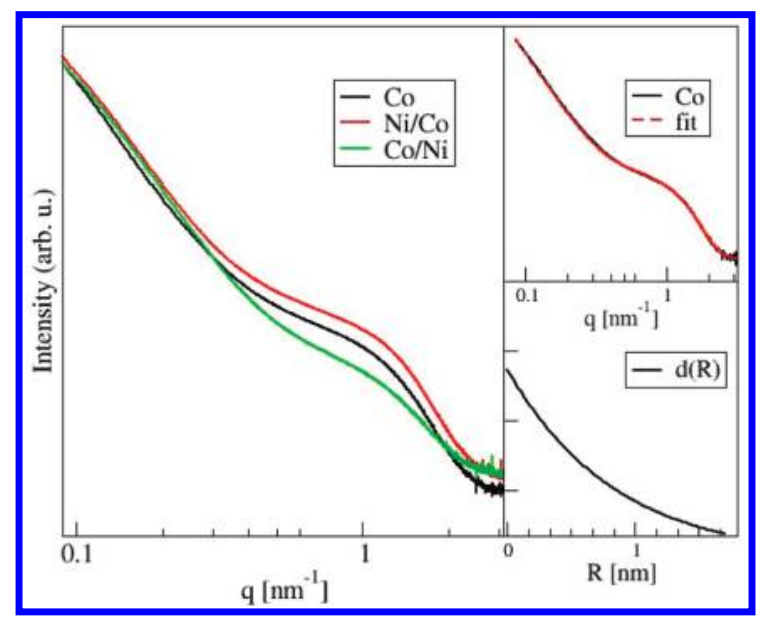

Figure 8. Experimental SAXS curves of the $\mathrm{Co}, \mathrm{Ni} / \mathrm{Co}$, and $\mathrm{Co} / \mathrm{Ni}$ samples. (Inset) experimental and fitted SAXS curves for Co nanoparticles and the corresponding size distribution function.

fitting procedure a scale factor and an isotropic displacement parameter were also optimized. The average diameters resulting from the fitting procedure are summarized in the second column of Table 5 .

In order to check the structural features (size and shape) of nanoparticles, SAXS experiments were also performed. The SAXS patterns of $\mathrm{Co}, \mathrm{Co} / \mathrm{Ni}$, and $\mathrm{Ni} / \mathrm{Co}$ samples are shown in Figure 8. An example of SAXS analysis, which considers a spherical shape of metal nanoparticles (radius $1.68 \pm 0.15 \mathrm{~nm}$ ), is reported in the inset panel of Figure 8. However, in the fitting it was necessary to include a Porodian component. Since the larger aggregates responsible for such a component cannot be attributed to metal particles (as confirmed by the WAXS data), they are most probably due to inhomogeneities arising from the typical supramolecular structure characterizing the surfactant matrix in which the metal clusters are embedded. It is important to notice that the cluster sizes $(\langle d\rangle)$ obtained by WAXS and SAXS data analysis (see Table 5) are in good agreement. The exponential trend of the nanoparticle size distribution functions $D(R)$, shown in Figures 6 and 8, is consistent with the synthesis procedure: cobalt or nickel ions are confined in the core of the reverse micelles dispersed in the $n$-heptane solvent. $^{11,12}$

Due to the limited number of metal ions secluded in each micelle, it seems reasonable that small clusters are suddenly formed as a consequence of the reducing treatment. Then, the growth/coalescence processes leading to an increase of the cluster size should be statistically inhibited or slackened by the opportunely oriented surrounding surfactant anions and their adsorption at the nanoparticle surface.

\section{CONCLUSIONS}

By changing the time order of the chemical reduction of $\mathrm{Co}$ (II) and $\mathrm{Ni}$ (II) metal ions confined in the core of cobalt and nickel bis(2-ethylhexyl)phosphate reverse micelles dispersed in $n$-heptane, structurally different bimetallic nanoparticles composed of cobalt and nickel have been synthesized. Detailed knowledge on the nanoparticle size, size distribution, metal valence state, and surface and internal composition has been achieved by the synergic use of some X-ray-based techniques (XPS, EXAFS, WAXS, and SAXS). Data analysis consistently shows that all samples are composed of very small size and chemically stable nanoparticles (about $1-2 \mathrm{~nm}$ ). Both these features highlight the potentiality of the synthetic procedure and, in particular, that the coating effect of surfactant matrix is able to efficiently protect the nanoparticles from growth/coalescence and oxidation. The comparative analysis of experimental data reveals that the composition of the nanoparticle surface is strongly different from that of the core and that both compositions depend on the time order of the chemical reduction. As expected, the metals in oxidized form are mainly located at the nanoparticle surface, whereas the core is composed of atomic species in zero-valent state. In the case of $\mathrm{Ni} / \mathrm{Co}$ and $\mathrm{Co}+\mathrm{Ni}$ samples, some tendency of cobalt atoms to be preferentially located at the nanoparticle surface is observed.

Yamauchi and coauthors suggested that the nickel core acts as a catalyst for the redox reaction between $\mathrm{Co}^{2+}$ and oleylamine during the formation of the cobalt shell. ${ }^{13}$ In this case we used sodium borohydride as a reductant and metal bis(2-ethylhexyl)phosphate in $n$-heptane as precursors. According to the present results, the reduction process seems independent of the chemical nature of the metal core, 8,25 while it seems likely that the interaction between the metal and the surfactant plays a decisive role in the disposition of the different metal phases. Furthermore, we have found that nickel is less prone to be oxidized than cobalt, so the relevant presence of cobalt in the oxidized form of $\mathrm{Co}^{2+}$ in both the $\mathrm{Ni} / \mathrm{Co}$ and $\mathrm{Co} / \mathrm{Ni}$ samples confirms that it can quite easily interact with the surfactant molecules and migrate at the surface of the nanoparticles.

In conclusion, our results indicate that the control of the synthetic procedure of bimetallic nanoparticles in solutions of reverse micelles leads to a fine control of the metal spatial distribution within each nanoparticle, together with the ability to form very small and chemically stable nanoparticles. However, the occurrence of some atomic-scale physicochemical processes such 
as atomic migration, selective affinity of metal ions with the surfactant head group, and deposition rate should be taken into account because they could play a subtle role in determining the structural features of bimetallic nanoparticles.

\section{AUTHOR INFORMATION}

\section{Corresponding Author}

*E-mail alessandro.longo@cnr.it.

\section{ACKNOWLEDGMENT}

We acknowledge the European Synchrotron Radiation Facility for provision of synchrotron beam time (proposals MA-681 and $\mathrm{CH}-2765)$. Financial support from CNR, Università of Palermo and MIUR within the PRIN 2006 grant "Dalle singole molecole a complessi e nanostrutture: struttura, chiralità, reattività e teoria" is gratefully acknowledged. We thank Roberto Megna (CNR) for mechanical assistance in building the SAXS cell, and the staff of beamlines BM26 and ID31 of ESRF for the technical assistance during the measurements.

\section{REFERENCES}

(1) Chen, W.; Ghosh, D.; Sun, J.; Tong, M. C.; Deng, F.; Chen, S. Electrochim. Acta 2007, 53, 1150.

(2) Mirkhalaf, F.; Paprotny, J.; Schiffrin, D. J. L.Am. Chem. Soc. 2006, 128,7400 .

(3) Joseph, Y.; Besnard, I.; Rosenberger, M.; Guse, B.; Nothofer, H. G.; Wessels, J. M.; Wild, U.; Knop-Gericke, A.; Su, D.; Schlolgl, R.; Yasuda, A.; Vossmeyer, T. L.Phvs. Chem. B 2003, 107, 7406.

(4) Zhang, H.; Yao, T.; Sun, Z.; Li, Y.; Liu, Q.; Hu, F.; Pan, Z.; He, B.; Xie, Z.; Wei, S. I. Phvs. Chem. C 2010, 114 (32), 13596-13600.

(5) Hu, M. J.; Lu, Y; Zhang, S.; Guo, S. R.; Lin, B.; Zhang, M.; Yu, S. H. L.Am. Chem. Soc. 2008, 130 (35), 11606-11607.

(6) Yao, H.; Kurokami, M.; Kimura, K. Microelectron. Eng. 2009, $86,809$.

(7) Dong, T. Y.; Wu, H. H.; Lin, M. C. Langmuir 2006, 22, 6754.

(8) Longo, A.; Giordano, F.; Giannici, F.; Martorana, A.; Portale, G.; Ruggirello, A.; Turco Liveri, V. I. Appl. Phvs. 2009, 105, 114308.

(9) Ang, T. P.; Chin, W. S. I. Phvs. Chem. B 2005, 109, 22228-22236.

(10) Cheng, G.; Hight Walker, A. R. I. Magn. Magn. Mater. 2007, $311,31$.

(11) Turco Liveri, V. Controlled Synthesis of Nanoparticles in Microheterogeneous Systems; Kluwer Academic/Plenum Publishers: New York, 2005.

(12) Longo, A.; Portale, G.; Bras, W.; Giannici, F.; Ruggirello, A. M.; Turco Liveri, V. Langmuir 2007, 23, 11482.

(13) Yamauchi, T.; Tsukahara, Y.; Yamada, K.; Sakata, T.; Wada, Y. Chem. Mater. 2011, 23, 75.

(14) Steyler, D. C.; Jenta, T. R.; Robinson, B. H.; Eastoe, J.; Heenan, R. H. Langmuir 1996, 12, 1483.

(15) Shirley, D. A. Phys. Rev. B 1972, 5, 4709.

(16) Sherwood, P. M. A.; Briggs, D.; Seah, M. P. Practical Surface Analysis; Wiley: New York, 1990; p 181.

(17) Wagner, C. D.; Davis, L. E.; Riggs, W. M. Surf. Interface Anal. 1986, 2, 53.

(18) Klementev, K. V. L.Phvs. D: Appl. Phvs. 2001, 34, 209.

(19) Moulder, J. F.; Stickle, W. F.; Sobol, P. E.; Bomben, K. D. In Handbook of X-Ray Photoelectron Spectroscopy; Chastain, J., King, R. C., Jr., Eds.; Physical Electronics Inc.: Eden Prairie, MN, 1995.

(20) Tan, B. J.; Klabunde, K. J.; Sherwood, P. M. A. I.Am. Chem. Soc. 1991, 113 (3), 855.

(21) Borowski, M. I. Phvs. IV 1997, 7, C2-259-C2-260.

(22) Kitakami, O.; Sato, H.; Shimada, Y.; Sato, F.; Tanaka, M. Phvs. Rev. B 1997, 56, 13849.
(23) Cattaruzza, E.; Battaglin, G.; Canton, P.; de Julián Fernández, C. Ferroni, M.; Finotto, T.; Maurizio, C.; Sada, C. L. Non-Cryst. Solids 2004, 336, 148.

(24) Longo, A.; Martorana, A. L. Appl. Crystallogr. 2008, 41, 446.

(25) Pileni, M. P. Langmuir 1997, 13, 3266-3276. 